\title{
El relato de un padre ante circunstancias vividas en una Unidad de Cuidados Intensivos Neonatales
}

\author{
The story of a father about the circumstances experienced in a Neonatal \\ Intensive Care Unit
}

\begin{abstract}
El que sigue es el relato de un padre. Sus vivencias, sentimientos y reflexiones tras los largos meses de internación de sus hijos mellizos: varón y mujer, quienes nacieron demasiado tempranamente para la fecha en la que deberían haberlo hecho. El contexto para el cual fueron escritas las presentes reflexiones fue el Primer Encuentro Nacional de Humanismo en Medicina organizado por la Sociedad Argentina de Pediatría en el mes de abril de 2013. Ambos padres fueron invitados a participar de una sesión convocada bajo el título "Qué nos dicen los pacientes".
\end{abstract}

¿Qué puede agregar un padre al relato de una madre? Hemos conversado durante meses con mi esposa acerca del relato de las vidas de nuestros hijos y el pasaje de Helena. Digo pasaje, como quien dice un tránsito hacia otro modo del ser (o el no-ser). O hacia el reconocimiento de la solidaridad entre los vivos y los muertos y las recónditas maneras de evocación y de diálogo. Mi esposa ha hecho un bello relato de la epopeya de Helena en este mundo, de su permanencia a nuestro lado hasta que decidió dejarse ir definitivamente, con un susurro bello y exacto, como un acorde al final de una obertura. Lo nuestro no fue sino respetar una voluntad que era inexorable en ella.

¿Qué sabe un padre, qué puede decir? Los padres, dicen, no tenemos un vínculo tan visceral con los niños; ni siquiera llevan nuestros nombres de familia en sus cunas -solo es la ley la que los inscribe en un linaje-. La paternidad parece un asunto administrativo o putativo, una investidura simbólica -la maternidad un hecho natural-. Si a la madre la naturaleza que la sociedad le concede la ata a las cunas de los niños como subrogados de su vientre, el padre permanece en un limbo hasta que media el reconocimiento legal. En una situación de internación, los padres flotamos a la deriva, sin rumbo en un mar de desolación. Nuestros hijos no tienen nuestros nombres; nacieron sin deber haber nacido y se debaten en un cruel purgatorio que no es vientre ni tampoco vida. Poco se espera de nosotros los padres en relación a los niños -a lo sumo, debemos cumplir labores de cuidado con una torpeza digna de caballeros-, pero es siempre la madre a la que se convoca como conocedora de sus hijos, se la dota de abnegación y saber maternal. También es a la madre a la que se le exige el sacrificio y a la que se juzga más duramente. Los padres, sin embargo, sabemos también de nuestros hijos. La madre, puérpera a destiempo, está alienada a sus crías -en una escenografía montada que reproduce un orden natural roto: las incubadoras, la nutrición parenteral, el amamantamiento mecánico; la tecnología como sustituto necesario pero grotesco-. El padre, de pie en los corredores o impávido cerca de sus hijos, bebe la angustia o se evade de maneras más o menos dignas. Pero el padre, en ese yermo no-lugar de quien aguarda lo fausto o infausto, también sabe. Muchos no saben que saben, otros creen no saber, otros dicen no saber tanto como las madres. Apartado a un lado, hasta que la suerte se decida, el padre percibe a veces con mayor crudeza. Y no lo sabe decir.

¿Qué sabe un padre acerca de sus hijos? Sabe de sus antepasados: de sus abuelos, bisabuelos; sabe de la historia familiar con sus vaivenes de dichas y penurias; de guerras, exilios y pérdidas. También de esperanzas y anhelos. Conoce la trama a la que sus hijos advienen. No es saber poco. Sabe también, sin saberlo, de sus genes y su historia. Y sobre todo, sabe de su sistema de valores, de sus convicciones materiales y espirituales. Un padre sabe cómo preservar la dignidad de su hijo. "Dignidad" viene de una antigua raíz que evoca el pensamiento y la aceptación. Un padre debe poder "dignificar" a su hijo aun allí donde su cosmovisión sea resistida por el discurso dominante acerca de lo que un padre o una madre "deben" querer. Un buen padre sabe honrar la vida de sus hijos -incluso cuando debe aceptar un final aciago y obrar en consecuencia- de acuerdo con sus convicciones éticas, religiosas y humanas. Un padre debe poder también honrar la muerte de un hijo. Debe poder discriminar cuál es el límite. 
Los padres -a la deriva en los servicios de neonatología, sumidos en nuestros pesarespodemos hacer más que cumplir funciones maternas sustitutas. Los que permanecemos allí, al costado de las cunas, al flanco de nuestras esposas, debemos velar por la dignidad, la honorabilidad y la humanidad de nuestros hijos -cualquiera sea la definición que cada padre y madre otorgue a esas palabras-. Y, de ser necesario, un padre y una madre deben ser capaces de preservar a sus hijos de la propia medicina. Hoy, en muchos casos, los equipos de salud ofrecen una atención denodada y cuidadosa de los niños -e incluso a menudo ofrecen contención y apoyo a los padres más allá de lo estrictamente pautado-. Su labor es invaluable. Pero son sólo los padres quienes pueden ver en ese niño -que en muchos casos no debería haber aún nacido, en ese niño que sufre y batalla-, solo los padres llaman a ese niño "hijo". Es solo a los padres -y su familia ampliada- a quienes esos niños "duelen" como hijos. Es a los padres a quienes se les va la vida allí. Porque hacen de ese niño un "hijo", un "hermano", un "nieto". Porque inscriben a ese hijo en una genealogía, en un linaje y-de manera más amplia- en una cosmovisión, con sus dioses, sus creencias y sus concepciones sobre la vida, la muerte y, en última instancia, sus preguntas sobre el ser. No es justo reclamar que la medicina humanice de tal manera a sus pacientes que pierda cualquier orientación científica o procedimental. Si eso sucediera, la medicina perdería efectividad como disciplina. Tampoco, es cierto, todos los padres, ante situaciones de vida o muerte, pueden adoptar una posición ética irrenunciable -ni tampoco es condición imprescindible que lo hagan, si no lo desean-. Esta es tan solo nuestra historia; nuestro testimonio. Otros padres tendrán otras historias de dolor y esperanza que ojalá quieran compartir. Este testimonio -que puede que haya sido o que llegue a ser también la historia de otros- es sólo único en cuanto se trató de nuestros hijos y su odisea. También en buena medida es singular porque el desenlace de la "historia de internación" tuvo un giro final inesperado que nos sobrecogió a todos.

La diferencia es que, en nuestro caso, tuvimos que poner un freno, aun en contra de nuestros propios sueños e ilusiones. La complicación última de nuestra hija solo puso en evidencia lo ominoso de su condición. Fue un amargo reconocimiento. Creímos entender entonces lo que ya sospechábamos mucho tiempo antes: nuestra hija no deseaba esa vida, ni deseaba seguir luchando como deseábamos que siguiera haciéndolo. Y de pronto, no nos extrañó. Helena había vivido sus últimos tres meses antes de deber haber siquiera nacido. Es una situación tan paradójica que no basta el lenguaje para expresarlo. ¿No era demasiado pedir? ¿Y si no quería? ¿O no podía seguir adelante? Entonces tuvimos que poner en palabras lo que creímos que ella nos estaba diciendo. Déjenme partir. $Y$ entonces, fuimos su voz. No hubo desacuerdos ni vacilación entre nosotros. Ambos comprendimos que ese era su límite y, también, su voluntad. Sin duda fue un acto osado y cuestionable para muchos. Pero antes que dejar a nuestra hija librada a una terapéutica que ya no tenía más que ofrecerle en pos de un futuro digno, antes de que pudiera siquiera convertirse en objeto vano de experimentación médica, fuimos nosotros quienes abogamos por su dignidad. Solicitamos que se convocara de urgencia un Comité de Ética y hablamos inspirados y resueltos ante el cuerpo médico. Y así, el comité ponderó -escuchando nuestro relato- la delicadísima condición de nuestra hija y pudo aceptar la indignidad que suponía la prolongación de un tratamiento cada vez más invasivo e inconducente. A veces el diálogo abierto es el instrumento médico más enérgico: es el modo en que reconocemos la "humanidad" que nos constituye y nos hermana al otro. Es la palabra humanizada la que trasciende, en los instantes cruciales, la jerga técnica del especialista y amarra el ser a la irrevocable condición humana, con sus ciclos de vida y muerte. La mortalidad es un límite del hombre, pero también su derecho más inalienable. Es así que pudimos soltar a nuestra hija de las ataduras de la omnipotencia médica y técnica, con sus promesas milagrosas de sanación u otras terapéuticas superadoras, y contemplarla en su frágil humanidad. Pudimos entonces ofrecerle una muerte bella -y dejarla partir-. A ella, a Helena, quien exhalando su alma, nos consagró su tiempo de vida como un enigma.

La nuestra ha sido una experiencia sobre los "límites". No sólo porque la situación de nuestros hijos era límite desde el inicio, al igual que la de muchos de los niños internados en las unidades de neonatología, sino porque confronta a la medicina también con sus propios límites. Creemos que especialmente en situaciones de vida o muerte -o en las que se corre el riesgo de vulnerar la dignidad humana- la medicina como disciplina deber ser capaz de un posicionamiento 
que vaya más allá de las respuestas de avanzada técnica y científica merced a las cuales ofrecen más y mejores terapéuticas para los padecimientos humanos. No es justo ni posible que se espere de la medicina todas las respuestas, ni menos aun que se le reclame infalibilidad o un éxito garantizado. Es por eso también que la medicina en los instantes terminales y de zozobra no puede replegarse sobre un discurso técnico-científico basado en las causas y efectos o en las estadísticas o en las terapéuticas paliativas sino que debe abrazar el tan mentado humanismo. Es así que la medicina -en casos límite- puede y debe renunciar a la exigencia (sin duda, también social) de ofrecer todas las respuestas y ceder el terreno para la reflexión acerca de la vida y la muerte, la integridad humana o las preguntas por el ser. $Y$ ocupar así un lugar indispensable en las ciencias del hombre.

Gastón Basile

gastonjbasile@yahoo.com

http://dx.doi.org/10.5546/aap.2014.116 